\title{
THE TECHNIQUE OF BONE MARROW ASPIRATION IN CHILDREN
}

\author{
BY \\ JOHN L. EMERY \\ From the Department of Pathology, the Children's Hospital, Sheffield
}

(RECEIVED FOR PUBLICATION NOVEMBER 9, 1956)

Bone marrow aspiration has now been an established procedure in haematology for close on 50 years (Pianese, 1905), but it has been only during the last two decades, following the studies of Kato (1937), Vogel and Bassen (1939), and Diwany (1940), that a study of bone marrow has become routine procedure in the diagnosis of an increasing variety of diseases in children.

The aim of this communication is to present the technical procedures that have been arrived at in an active children's hospital.

No attempt will be made to discuss the cytological aspects of bone marrow in infants, which have been the subject of much study (Eberhard, Etcheverry, and Hille, 1946; Britton and Neumark, 1949) and are well presented by Whitby and Britton (1957).

\section{The Needle}

The Sala type needle has been satisfactory in all instances in the author's hands, its only disadvantage being that it is a little heavy, and if unsupported when in the marrow cavity it is frequently held insufficiently rigidly by the outer bone, and can easily fall out. Attempts to use needles of small gauge, with the idea that such would be more suitable for infants, have been unsatisfactory, and the Sala type needle would seem to be the smallest calibre suitable for obtaining satisfactory aspiration for either smear or histology.

Needles are re-sharpened to a short bevel every time before use in the sterile supply service of the hospital, using a fine grindstone and a cold slowrunning spindle. Using this system it seems certain that the needle cuts the skin and periosteum with less pain than is caused by the usual hypodermic needle inserting the conventional local anaesthetic.

\section{Sites of Puncture}

Sternum.-The sternum is perhaps the least suitable site in the child. The manubrium, which is the only convenient area, is often freely mobile on the clavicle and ribs and cannot be held firm. This site, which to the child is the bottom of the neck, is alarming to approach to any conscious child, and to extend the head and neck and lift the arms requires a considerable depth of unconsciousness to prevent the child being disturbed. Further, the child itself requires the services of at least two assistants, one to hold the head and arms, and the other to steady the lower trunk and legs. While most of the accidents associated with marrow puncture have been related to sternal punctures (Fortner and Moss, 1951 ; Editorial, J. Amer. med. Ass., 1954 ; Editorial, Lancet, 1948), this site has in the past been used so relatively frequently that it is not possible to obtain a fair estimate of the risks, but it is reasonable to assume that there is greater risk of an over-shot needle being more danger here than in almost any other area of the body.

For these reasons and the much greater ease of access of other bones, marrow aspiration from the sternum in a child has not been attempted for many years in this hospital.

Tibia.-After the femur, the tibia was the earliest bone used for marrow biopsy (Ghedini, 1910). It contains active marrow at its upper end throughout the whole of childhood, and marrow has been successfully aspirated from the tibia in children at the age of 10 years. It is the usual practice to use the tibia as the primary site of puncture in all children under the age of 2 years. The area for insertion is on the upper flat non-muscular surface, and the best point would seem to be about $2 \mathrm{~cm}$. obliquely from the insertion of the patellar tendon, this latter being often the only certain landmark in an obese infant. If the needle is inserted lower in the shaft, difficulty is likely to be experienced due to rapid thickening of the bony cortex and narrowing of the lumen. The growing bone is illustrated in Fig. 1. It will be seen how rapidly the cortex thickens, and how relatively high in the shaft the 
nutrient artery enters. The best site for puncture is in the relatively thin plate just distal to the growing edge, and this remains a constant distance from the end of the bone.

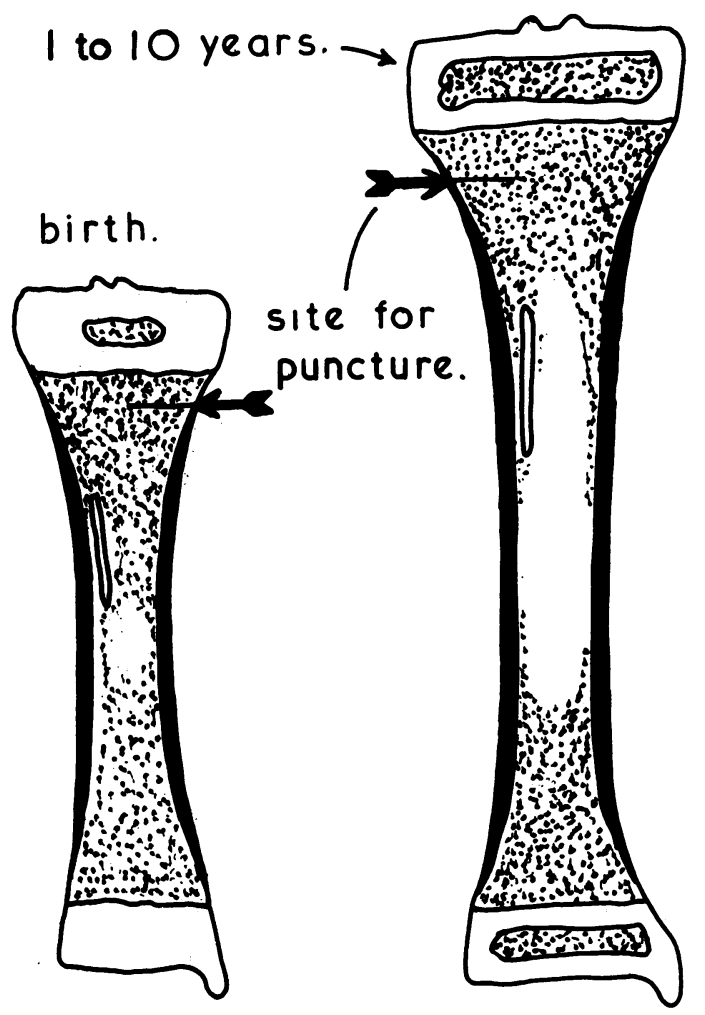

FIG. 1.-Diagram of the tibia at birth and in later childhood, indicating the optimal site for marrow puncture and the relationship of this part to the end of the bone.

Anterior lleum.-The usual approach in the adult is from the lateral surface through the muscle mass owing to the relative thickness of the outer bone along the upper margin compared with the lateral surface. In an infant this upper bone is not so well developed as in the adult, and it has always been found more convenient to approach the marrow of the ileum through the crest itself. The most convenient procedure is to stand to the left side of the lying child, and to place the left hand upon the abdomen, pointing the centre finger to the umbilicus and holding the crest of the ileum between the thumb and first finger. In this position it is easy to orientate the anterior portion of the ileum and to insert the needle midway between one's finger and thumb. The anterior iliac crest, however, does not appear to be the best site for puncture, for the following reasons : First, the child has to be fairly deeply anaes- thetized in order to enable one to extend the legs $\underline{\text { 을 }}$ from the abdomen. Secondly, if the child is dis- $\vec{F}$ turbed at all, the abdominal muscle becomes tense $\stackrel{0}{?}$ and it is almost impossible to approach the crest from the top, and to approach it laterally in a slightly struggling child is a somewhat precarious $\vec{\nabla}$ procedure. Furthermore, the anterior crest of the $\unrhd$ ileum in an older child is the site of several \& secondary centres of ossification (Fig. 2), and the $\vec{\theta}$

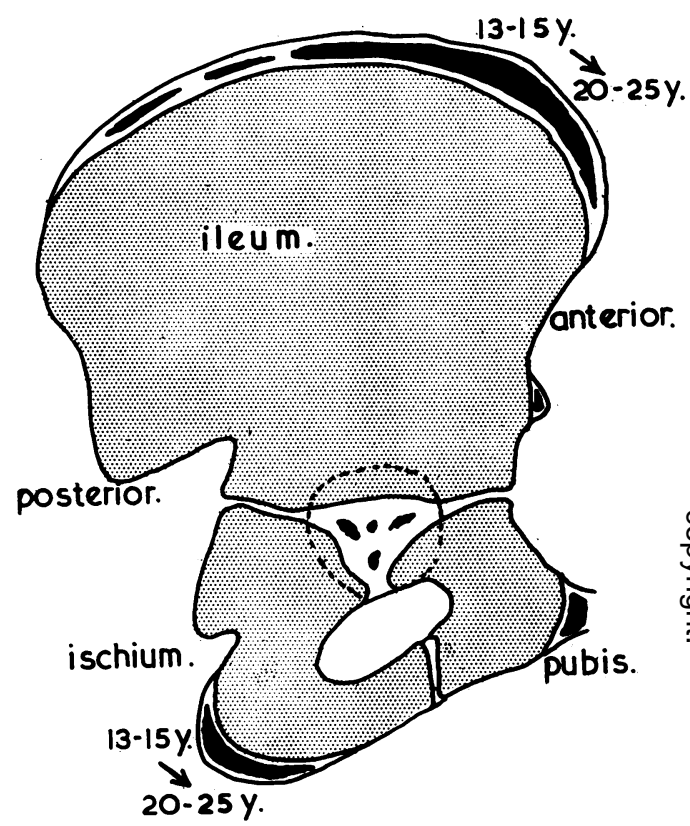

FIG. 2.-Diagram of the development of the ileum showing the secondary centres of ossification in the anterior iliac crest.

end of the needle can well be between the layers 옹 of bone and cartilage, or if one is attempting to approach the crest from the lateral surface the 3 . needle may hit the region between the epiphysis and the main ileum.

Posterior Ileum.-The posterior ileum would, 을 however, appear to suffer from none of the disadvantages of the anterior crest.

The posterior crest of the ileum is one of the $\bar{N}$ widest areas of bone in the body that is imme- $O$ diately deep to the skin and connective tissue and $N$ is an established site for puncture in the adult $\underset{\mathrm{E}}{ }$ (Bierman and Kelly, 1956). There are no impor- 우 tant nerves or vessels near it.

A further great advantage is that the child is $\frac{0}{D}$ approached from behind and can be held in a ? curled-up sleeping posture throughout the whole 0 of the procedure. This is the child's uterine posture. This posture has a further advantage in $\mathbb{\mathbb { D }}$ that the child can be held by a single assistant, 
and almost all nurses are experienced in holding children in this position for the purposes of cerebrospinal fluid puncture. The method of holding and site of insertion are indicated in Fig. 3. The assistant places her left arm around the child's head and shoulders, and the other beneath the child's thighs. By holding her own hands, she now has virtual control of the child, and can lift it around on the examination couch without disturbance. In this position a child, who if one stretched out its legs would immediately wake up

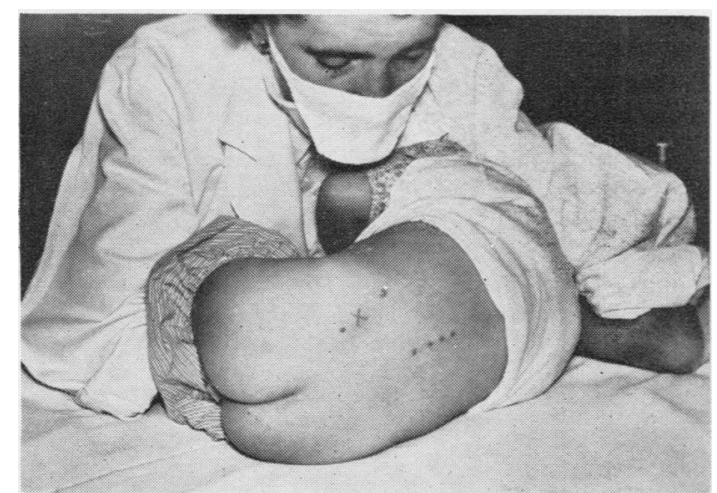

FIG. 3. - Photograph of a child being held for either posterior iliac puncture, spinous process puncture, or for obtaining cerebrospinal fluid. A small cross indicates the site for inserting the marrow aspirating needle.

and struggle, remains asleep, and, although it may awaken during the puncture procedure, will have no recollection whatsoever of the incident later.

Since doing this procedure there have been no failures, and theoretically it would seem that this site would be just as convenient for the child under the age of 2 years as over, but the tibia is still used in the younger child, first because there has never been any difficulty with the tibia, and second because there is a greater likelihood of infection getting through a puncture wound in this region in a child still wearing a napkin and having wet urine around the buttocks.

Vertebral Spinous Process.-The vertebral spinous process may be used with relative ease with the child in the "lumbar puncture" posture. The approach is directly into the tip of the spinous process rather than from the side as is recommended in adults.

\section{Anaesthesia}

Generally speaking, unless there has been some special training instituted, a child resents a "prick" more than any other procedure in the wards. Marrow puncture cannot be a com- pletely painless procedure, as pain is produced by the suction of the bone marrow. For that reason it does not appear justifiable to do marrow punctures without some form of basal analgesia in children between the ages of 1 and 10 years.

The routine procedure is to have the child in a semi-stuporose state by the use of rectal pentothal (Lorber, 1950). It is not necessary to have the child deeply unconscious, as, although the child may awake, and perhaps struggle a little during the operative procedure, it has been found that it has no recollection of the procedure when it has recovered from the basal anaesthetic. The child does not resent an approach to the anus, and this route appears to be preferable to any form of oral premedication. The dose of pentothal given is related to the weight of the child, and the copy of the dose weight chart that is on the hospital wards is reproduced in Table I. The question of

TABLE I

DOSES OF RECTAL THIOPENTONE RELATED TO WEIGHT

\begin{tabular}{c|c}
\hline Weight of Child (lb.) & Dose of Thiopentone (g.) \\
\hline $7 \cdot 5-12.5(3.40-5.67 \mathrm{~kg})$. & 0.2 \\
$12.6-17.5(5.71-7.93,)$, & 0.3 \\
$17.6-22.5(7.98-10.20,)$, & 0.4 \\
$22.6-27.5(10.25-12.47,)$, & 0.5 \\
$27.6-32.5(12.51-14.74,)$, & 0.6 \\
$32.6-37.5(14.79-17.01,)$, & 0.7 \\
$37.6-42.5(17.06-19.28,)$, & 0.8 \\
$42.6-47.5(19.32-21.54,)$, & 0.9 \\
$47.6-52.5(21.59-23.81,)$, & 1.0 \\
\hline
\end{tabular}

local anaesthesia always arises, particularly if the child is not unconscious. The pain of the infiltration of the skin appears to be virtually indistinguishable from that of a sharp puncture needle.

\section{Summary}

The optimum site of puncture for children under the age of 2 years is the upper end of the tibia and for older children the posterior crest of the ileum.

Rectal thiopentone is a highly satisfactory form of basal anaesthetic for this procedure.

\section{REFERENCES}

Bierman, H. R., and Kelly, K. H. (1956). Blood, 11, 370.

Britton, C. J. C., and Neumark, E. (1949). Bone Marrow Biopsy, by S. J. Leitner. Churchill, London.

Diwany, M. (1940). Arch. Dis. Childh., 15, 159

Eberhard, R., Etcheverry, R., and Hille, A. (1946). Rev. chil.Pediat., $17,439$.

Editorial (1954). J. Amer. med. Ass., 156, 992.

- (1948). Lancet, 1, 566.

Fortner, J. G., and Moss, E. S. (1951). Ann. intern. Med., 34, 809.

Ghedini, G. (1910). Wien. klin. Wschr., 23, 1840.

Kato, K. (1937). Amer. J. Dis. Child., 54, 209.

Lorber, J. (1950). Brit. med. J., 2, 21.

Pianese, G. (1905). Gazz. int. Med. (Napoli), 8, 265.

Vogel, P., and Bassen, F. A. (1939). Amer. J. Dis. Child., 57, 245.

Whitby, L. E. H., and Britton, C. J. C. (1957). Disorders of the Blood, 8th ed. Churchill, London. 